\title{
Ambiente empresarial, posicionamento estratégico e modelo delta: um estudo de caso no segmento de transmissão de energia elétrica
}

Plínio Fernando da Cruz

Mestre em Administração - Fundação Pedro Leopoldo. Professor do Departamento de Engenharia Elétrica da Faculdade Pitágoras. Minas Gerais, Brasil

pliniofernando@yahoo.com.br

Bruno Pellizzaro Dias Afonso

Doutor em Administração - Universidade FUMEC. Professor do Instituto Federal do Norte de Minas Gerais. Minas Gerais, Brasil brunopdafonso@gmail.com

Emerson Antônio Maccari

Doutor em Administração - USP. Diretor do Programa de Pós-Graduação em Administração - PPGA - UNINOVE.Minas Gerais,Brasil

emersonmaccari@gmail.com

Tarcisio Afonso

Ph.D em Administração - Ohio University. Professor da Fundação Pedro Leopoldo. Minas Gerais, Brasil

professortarcisioafonso@gmail.com

\section{Editor Científico: José Edson Lara}

Organização Comitê Científico

Double Blind Review pelo SEER/OJS

Recebido em 27.02.2017

Aprovado em 03.04.2017

Este trabalho foi licenciado com uma Licença Creative Commons - Atribuição - Não Comercial 3.0 Brasil 


\title{
Resumo
}

O sistema elétrico brasileiro, nascido por investimentos governamentais, manteve sua origem pública e consagrou grandes empresas estatais de energia. Após a implantação da Agência Nacional de Energia Elétrica (ANEEL), em 1998, acentuouse a alternância do modelo estatal para o privado. O presente estudo buscou analisar a estratégia de uma empresa multinacional, pioneira no setor de transmissão de energia elétrica, para adaptar-se às mudanças na regulação da indústria e no aumento de competição. Foi utilizada a metodologia qualitativa de análise, tendo como referência teórica o Modelo Delta de posicionamento estratégico. Os dados foram coletados por meio de entrevistas orientadas por questionário semiestruturado, envolvendo o corpo de diretores e gerentes da empresa, e foram interpretados utilizando a análise de conteúdo. Os resultados da pesquisa demonstraram que as estratégias adotadas pela empresa, após as mudanças no ambiente empresarial, podem ser explicadas à luz do modelo Delta de Hax e Wilde II (2001). Concluiu-se que as estratégias adotadas pela empresa foram eficientes para mantê-la na liderança do mercado e que o Modelo Delta constituiu um importante método para a análise de posicionamento estratégico.

Palavras-chave: Ambiente Empresarial; Posicionamento Estratégico; Modelo Delta; Setor de Transmissão de Energia.

\section{Business environment, strategic positioning and delta model: a case study in the segment of transmission of electrical energy}

\begin{abstract}
The Brazilian electric system, born of government investments, has maintained its public origin and consolidated large state-owned energy companies. After the implementation of the National Electric Energy Agency (ANEEL) in 1998, it has accentuated the change from the state to the private model. The present study sought to analyze the strategy of a multinational company, pioneer in the electric power transmission sector, to adapt to changes in industry regulation and increased competition. The qualitative analysis methodology was used, having as theoretical reference the Delta Model of strategic positioning. Data were collected through semistructured questionnaire aided interviews, involving the company's board of directors and managers, and were interpreted using content analysis. The results of the research demonstrated that the strategies adopted by the company, after the changes in the business environment, can be explained in the light of the Delta model of Hax \& Wilde II (2001). It was concluded that the strategies adopted by the company were efficient to keep it in the lead of the market and that the Delta Model was an important method for the strategic positioning analysis.
\end{abstract}

Keywords: Business Environment; Strategic Positioning; Delta Model; Energy Transmission Sector. 


\section{Entorno empresarial, posicionamiento estratégico y modelo delta: un estudio de caso en el segmento de transmisión de energía eléctrica}

\section{Resumen}

El sistema eléctrico brasileño, nacido de las inversiones gubernamentales, ha mantenido su origen público y consolidado grandes empresas estatales de energía. Luego de la implementación de la Agencia Nacional de Energía Eléctrica (ANEEL) en 1998, se acentuó el cambio del modelo estatal al privado. El presente estudio trató de analizar la estrategia de una empresa multinacional, pionera en el sector de transmisión de energía eléctrica, para adaptarse a los cambios en la regulación de la industria y el aumento de la competencia. Se utilizó la metodología de análisis cualitativo, teniendo como referencia teórica el Modelo Delta de posicionamiento estratégico. Los datos fueron recolectados a través de entrevistas guiadas por cuestionario semiestructurado, envolviendo el consejo de administración y directivos de la empresa, y fueron interpretados usando análisis de contenido. Los resultados de la investigación demostraron que las estrategias adoptadas por la empresa, después de los cambios en el ambiente empresarial, pueden explicarse a la luz del modelo Delta de Hax \& Wilde II (2001). Se concluyó que las estrategias adoptadas por la empresa fueron eficientes para mantenerlo al liderazgo del mercado y que el Modelo Delta fue un método importante para el análisis de posicionamiento estratégico.

Palabras clave: Entorno Empresarial; Posicionamiento estratégico; Modelo Delta; Sector de transmisión de energía.

\section{Introdução}

O sistema elétrico, nascido por investimentos dos estados, manteve sua origem pública e consagrou grandes empresas estatais de energia. Cada Estado da União possuía a sua empresa controladora, sendo os planos de investimento e expansão realizados na esfera do governo estadual. Em 1962 foi fundada a Centrais Elétricas Brasileiras (ELETROBRÁS) para controlar todas as empresas do setor elétrico e organizar a expansão do setor com uma visão de todo o país (ANEEL, 2008).

O modelo setorial, pautado pela organização do sistema Eletrobrás, garantiu a expansão expressiva dos segmentos de geração e transmissão de energia elétrica ao longo dos anos 1960 e 1970. Essa tendência viria a ser revertida, na década de 1980, tanto como reflexo das mudanças nas regras dos mercados financeiros 
internacionais como dos obstáculos à continuidade da captação interna de recursos (Januzzi, 2007).

Em 1970, com a criação de Itaipu, estabeleceu-se uma hierarquia funcional com concessionárias federais como supridoras regionais; concessionárias estaduais como supridoras de área; e outras concessionárias estaduais e empresas privadas responsáveis pela distribuição de energia elétrica, caracterizando o início do processo de centralização.

O desenvolvimento econômico foi acelerado, especialmente entre 1968 e 1974, período conhecido como "milagre brasileiro", com elevados índices de crescimento da economia e vultosos investimentos no setor de infraestrutura (FUSP, 2015).

A seguir, nos anos 80, o modelo mostrou suas deficiências, repercutindo negativamente na situação econômico-financeira das concessionárias. O modelo centralizado com o sistema de tarifas equalizadas e remuneração limitada teve o efeito de estímulo à ineficiência administrativa, uma vez que penalizava as empresas mais eficientes (Januzzi, 2007).

Diante desse contexto, o Brasil passou a experimentar nova onda de privatização a partir de 1992, quando foi proposto o Plano Nacional de Desestatização (PND) do governo de Fernando Collor de Mello (1990-1992), tendo sido definida como prioridade a venda das distribuidoras, facilitada no período de 1992 a 1994, por meio da Lei n 8.631/1993 implementada no período do governo seguinte (FUSP, 2015).

Por outro lado, intensas transformações marcaram a história do Setor Elétrico Brasileiro (SEB) nas últimas décadas. Uma das mais significativas ocorreu em 26 de dezembro de 1996, com a criação da Agência Nacional de Energia Elétrica (ANEEL). Estava inaugurada uma nova era da regulação e da fiscalização do serviço público de energia elétrica no país.

A reestruturação do Sistema Elétrico Brasileiro (SEB) iniciou-se, de fato, em 1998, com a decisão do Ministério de Minas e Energia (MME) de desverticalizar as atividades de geração, transmissão, distribuição e comercialização de energia elétrica.

A ANEEL, organizada como autarquia especial vinculada ao Ministério de Minas e Energia, sucedeu o antigo Departamento Nacional de Águas e Energia Elétrica (DNAEE). Passou a atuar de forma mais intensa nos setores de concessão, $@$ Revista Gestão \& Tecnologia, Pedro Leopoldo, v. 17, n. 1, p. 181-206, jan./abr. 2017184 
regulação, mediação e, ainda, na fiscalização dos serviços concedidos. As atribuições da ANEEL são: regular e fiscalizar a geração, a transmissão, a distribuição e a comercialização da energia elétrica no Brasil (FUSP, 2015).

Com o advento da ANEEL, o modelo competitivo estatal-privado, já em declínio devido ao Plano Nacional de Desestatização de 1992, foi sensivelmente alterado para o privado-privado. Diante do novo modelo de concessão, realizado por meio de concorrências públicas, alinhado a um forte investimento no setor de geração, transmissão e distribuição (GTD) e um mercado interno repleto de grandes projetos de transmissão, rapidamente grandes players do mercado externo de energia viram no Brasil uma excelente oportunidade de novos negócios.

Neste novo modelo, os leilões de concessão do serviço público de transmissão são organizados pela ANEEL e realizados na Bolsa de Valores de São Paulo (BOVESPA), com inversão da ordem de fases, ocorrendo a habilitação dos proponentes apenas após a divulgação das propostas vencedoras. Os primeiros lances são feitos em envelope fechado e quando ocorrerem propostas com apenas $5 \%$ de diferença entre si, esses proponentes passam a uma fase de lances em vivavoz (Carvalho, 2011).

Foi também criada a Receita Anual Permitida (RAP), correspondente ao pagamento recebido pelas concessionárias de transmissão pela disponibilização de suas instalações, para a prestação do serviço público de transmissão de energia elétrica. Como o setor de transmissão de energia elétrica é remunerado pela RAP, a ANEEL deve estabelecer o valor da receita para cada concessão. Nas licitações, o valor da RAP estabelecido pela ANEEL é usado como a receita teto da concessão, isto é, o valor máximo que o proponente deve ofertar.

Entre 1999 e 2010 foram realizadas três concorrências e 21 leilões, totalizando aproximadamente 38.100 quilômetros de linhas de energia elétrica e 53 GVA de aumento de capacidade. A única diferença entre as concorrências e os leilões é que, nas primeiras, os proponentes davam apenas um lance em envelope fechado. Dos 112 lotes que tiveram seus lances avaliados, o deságio médio dos lotes que não tiveram lance em viva-voz foi de $31 \%$, enquanto que para os lotes que tiveram, foi de 33\% (Carvalho, 2011).

Em 2005 foram assinados os contratos de concessão para a implantação de 2.747 quilômetros de 10 novas linhas de transmissão. As obras significaram 
investimentos de $R \$ 2,06$ bilhões e deveriam estar concluídas até 2007 . As linhas foram arrematadas em leilão realizado em 2004 por 10 empresas brasileiras e três espanholas (CEMIG, 2016).

Com grandes leilões de transmissão de energia ocorrendo no país e com a abertura de mercado, permitida a partir do modelo regulado pela ANEEL, grandes empresas internacionais enxergam no Brasil oportunidades para bons investimentos e os leilões do setor elétrico começam a ser frequentados por empresas internacionais.

No ano de 2013 aconteceram grandes leilões. Em destaque, tem-se o leilão $n^{\circ}$ 01/2013, em que, dos seis lotes ofertados, quatro foram vencidos por empresas espanholas (Isolux e Abengoa), com deságio médio de $20 \%$. Nesse mesmo ano, o leilão $n^{\circ}$ 13/2013 leiloou a linha de transmissão da Usina Hidrelétrica de Energia UHE de Belo Monte, com 2.092 km de extensão, vencido com 38\% de deságio pelo consórcio IE Belo Monte, liderado pela gigante chinesa State Grid (ANEEL, 2013).

Com elevado número de projetos a serem iniciados e face ao deságio lançado nos leilões, os clientes precisam adquirir as torres para as linhas de transmissão com o mínimo preço possível, incrementando a competição entre os fabricantes do setor.

Dessa forma, percebeu-se a necessidade de estudar empresas deste setor, tendo em vista a mudança no ambiente empresarial, com a prevalência de um mercado mais competitivo e invasão de muitos players internacionais. Visando a esse objetivo, foi conduzido um estudo, tendo como unidade de análise a empresa líder de mercado, a SAE Towers, pioneira no setor de transmissão de energia elétrica, tendo iniciado as suas operações no Brasil em 1951 e possuidora da maior capacidade instalada para a produção de linhas de transmissão do país.

Foi então formulado o seguinte problema de pesquisa: como ocorreu o processo de adaptação estratégica da SAE Towers frente às transformações ambientais no setor de linhas de transmissão? O objetivo desta pesquisa é relatar as transformações no ambiente empresarial, especificamente no setor de geração, transmissão e distribuição de energia elétrica, ocorridas no Brasil na década de 90; propor um modelo de análise de estratégias para embasar a investigação de posicionamento estratégico; identificar o posicionamento estratégico da empresa multinacional estudada, antes e depois da desregulamentação estatal, e estabelecer 
a importância do novo posicionamento estratégico para a competitividade da organização.

\section{Referencial Teórico}

\subsection{Mudanças no setor elétrico}

O setor elétrico é estratégico para o país e exerceu papel vital durante todos os processos de mudança na economia brasileira. Seu crescimento está diretamente vinculado à economia e ao crescimento do país. Dessa maneira, serão a seguir analisadas as principais mudanças da economia e do setor elétrico.

Em síntese, o período que se estendeu de 1946 (pós-guerra) a 1962 (criação da Eletrobrás) foi marcado por profunda alteração no modelo brasileiro de desenvolvimento econômico, que passou a privilegiar a participação do Estado em funções produtivas, financeiras e planificadoras (Gomes et al., 2006).

No final da década de 60, já no segundo governo militar, teve início um novo ciclo de expansão da economia (o Produto Interno Bruto - PIB cresceu a taxas superiores a $10 \%$ ao ano) e ocorreu a retomada do investimento do governo e das estatais em obras de infraestrutura. No grupo de empresas estatais, foram relevantes os investimentos hidrelétricos, naquela época, realizados tanto com geração interna de recursos da própria atividade quanto com empréstimos externos. Entre esses projetos, cabe destacar a entrada em operação da hidrelétrica de Furnas (1963), que marcou o início da implantação efetiva da interligação do sistema elétrico brasileiro, pois interconectou os sistemas de suprimento de Minas Gerais, São Paulo e Rio de Janeiro (Gomes et al., 2006).

No final da década de 70, a trajetória de crescimento equilibrado e autossustentado começou a ficar comprometida a partir da estratégia governamental de expor o setor de energia em políticas para captação de recursos externos e para o controle do processo inflacionário por meio de forte contenção tarifária (ANEEL, 2008).

Rompido o modelo de autofinanciamento, os investimentos passaram a depender, cada vez mais, da captação de financiamentos externos. No final da década de 80 a situação de falência do modelo de financiamento do setor gerou debates permanentes, na tentativa de superar a crise e desfazer os obstáculos 
institucionais, que colocavam em risco qualquer projeto de retomada do crescimento econômico. Importante resultado dessas discussões foram as aprovações das Leis 8.031 (de 12 de abril de 1990), 8.631 (de março de 1993), 8.987 (de 13 de fevereiro de 1995) e 9.074 (de 7 de julho de 1995), que estabeleceram os fundamentos do novo modelo, assentado na criação de um mercado competitivo de energia elétrica (Januzzi, 2007).

O esgotamento do modelo do setor elétrico, vigente em meados da década de 90, com inadimplência e ineficiência operacional das concessionárias públicas, a utilização das tarifas como mecanismo de controle inflacionário e a incapacidade do Estado-investidor na expansão da produção, frente ao crescimento da demanda, foi determinante para a reestruturação do setor elétrico. Diante da gravidade desse cenário, o governo federal iniciou a privatização do setor, em 1995, antes mesmo da existência de um novo marco regulatório, como forma de instaurar uma pressão reformista. A captação de capital externo, via desestatização, e o início da competição no setor, condicionavam-se à estabilidade na regulação de forma a reduzir os riscos dos investidores (Carvalho, 2011). Surgia assim a necessidade de instituir uma agência reguladora autônoma, capaz de blindar institucionalmente o setor elétrico, a ANEEL, a primeira agência reguladora do país. Com o início da operação da ANEEL em 1998, regulando o setor elétrico, consolidava-se a mudança do modelo estatal para o competitivo no setor.

A ANEEL definiu os limites de participação das empresas no mercado, medida essencial para evitar a concentração e a criação de monopólios privados. Estabelecidas as primeiras regulamentações do setor, outra medida marcou 0 funcionamento efetivo da ANEEL como organismo regulador: a assinatura dos contratos de concessão com as distribuidoras de energia, mecanismo legal que passou a permitir controle mais rigoroso sobre as empresas e instituiu os instrumentos de correção tarifária. A Agência conseguiu cumprir plenamente um dos vértices de sua missão institucional com a fiscalização das empresas concessionárias (ANEEL, 2008).

O atual modelo do setor elétrico brasileiro determina a existência de concorrência no setor de transmissão. Neste sentido, as empresas não concorriam pela conquista do consumidor ou pelo montante de energia que iriam transportar, mas pela concessão das atividades de instalar, operar e manter uma linha de transmissão mediante o recebimento de receita. As empresas, portanto, concorriam 
para entrar no mercado e prestar o serviço objeto dos contratos de concessão. Atualmente essa concorrência se dá por meio dos leilões de concessão do serviço público de transmissão (Carvalho, 2011).

Para investigar as mudanças estratégicas de empresas, submetidas a um ambiente empresarial em grande transformação, o presente estudo passou a pesquisar um modelo para análise de posicionamento estratégico.

\subsection{Modelo de análise de posicionamento estratégico}

Os modelos desenvolvidos por diferentes escolas de pensamento estratégico possuem uma interconexão em relação ao seu objetivo primordial. Em geral, os modelos de formulação estratégica têm o objetivo de apoiar as análises estratégicas como auxílio aos dirigentes das organizações, fazendo com que os participantes das discussões estratégicas opinem, discutam, critiquem e gerem novos desenvolvimentos aos modelos estratégicos vigentes (Toledo \& Valdés, 2003; Ponchirolli \& Fialho, 2016). Os modelos permitem aos dirigentes das organizações uma visão mais clara dos aspectos inerentes à formulação estratégica e sua aplicação em todos os níveis organizacionais (Ferreira, 2012).

O modelo das cinco forças de Porter (1991), apresentado no final da década de 1970, apresenta e discute cinco forças competitivas que têm foco na análise da competição na indústria. Como discutido por Castor, (2017), as cinco forças determinam a intensidade da competição no setor, tendo sido denominadas por Porter como: 1) ameaça de novos entrantes; 2) poder de negociação com fornecedores; 3) poder de negociação dos compradores; 4) ameaça de produtos ou serviços substitutos; 5) rivalidade entre as empresas existentes.

Para lidar com essas forças competitivas, Porter (1991) sugere a abordagem de três estratégias genéricas, das quais a organização deve selecionar preferencialmente apenas uma para obter sucesso: a) liderança no custo total; b) diferenciação; c) enfoque.

Nesse modelo, não é possível para as empresas ficarem no meio-termo, ou seja, tentarem praticar as estratégias de baixo custo e diferenciação ao mesmo tempo. Primeiramente, porque há inconsistência na cultura organizacional necessária. E em segundo lugar, porque ela irá perder ou os grandes clientes que 
buscam grandes volumes e pressionam por baixos preços ou as altas margens proporcionadas pelos clientes que buscam diferenciação. O cenário mais provável é o de que a empresa que selecione o meio-termo tenha baixa rentabilidade e não seja competitiva no mercado (Porter, 1986; Salavou, 2015).

Enquanto o modelo de estratégia competitiva proposto por Porter (1986) tem o enfoque no ambiente externo à organização, o modelo da visão baseada em recursos (Resource-Based View - RBV) dá mais ênfase aos recursos internos, em que as habilidades e capacidades dominadas por uma organização podem levá-la a um desempenho superior. Segundo Penrose (1959 como citado em Harrison, 2005), a empresa pode ser vista como uma estrutura que coordena atividades de diversos grupos ou pessoas, assim como um conjunto de recursos produtivos, que podem influenciar o desempenho competitivo. Nason \& Wiklund (2015) aprofundam a discussão sobre a visão penroseana, com foco na versatilidade dos recursos, e a teoria RBV, cujos princípios centrais dizem respeito a recursos que atendem a critérios Valiosos, Raros, Inimitáveis e Não substituíveis (VRIN).

A estratégia competitiva, fundamentada no modelo da visão baseada em recursos, encontrou proeminentes seguidores, entre os quais Hamel e Prahalad (1994) criadores do conceito de core competences. Segundo Hamel e Prahalad (1994, p. 27) "a competição pela liderança das chamadas competências essenciais, ou core competences precede a competição pela liderança de produtos e concebe a corporação como um portfólio de competências, bem como um portfólio de empresas". Os autores ressaltam ainda que a estratégia de uma empresa não deve ser baseada nos seus recursos atuais ou de seus concorrentes, mas sim na capacidade que a empresa ou seus concorrentes têm em dinamizar esses recursos (Bhawsar \& Chattopadhyay, 2015).

Para interpretar o processo estratégico no contexto do ambiente competitivo e globalizado contemporâneo, o Modelo Delta, de Hax e Wilde (2001), oferece um arcabouço diferenciado, como argumenta Aghazadeh (2015).

O modelo Delta nasceu da pesquisa do Professor Arnold Hax e do consultor de empresas Dean Wilde II, que durante quatro anos estudaram 100 empresas geograficamente localizadas nos Estados Unidos. Eles concluíram que a estrutura de Michael Porter não comporta todas as formas de competição do mercado atual. Dessa maneira, buscaram um novo modelo estratégico capaz de explicar esses desafios e o denominaram de "Modelo Delta". 
Hax e Wilde (2001) estabeleceram um novo modelo de posicionamento estratégico representado por um triângulo, que reflete uma estrutura de negócios diferente e suas muitas maneiras de competir, oferecendo três posições estratégicas: melhor produto; solução total para o cliente; e lock-in do sistema (Hax \& Wilde, 2001; Doligalski, Zaborek, \& Sysko-Romańczuk, 2015). A Figura 1 exemplifica esse modelo.

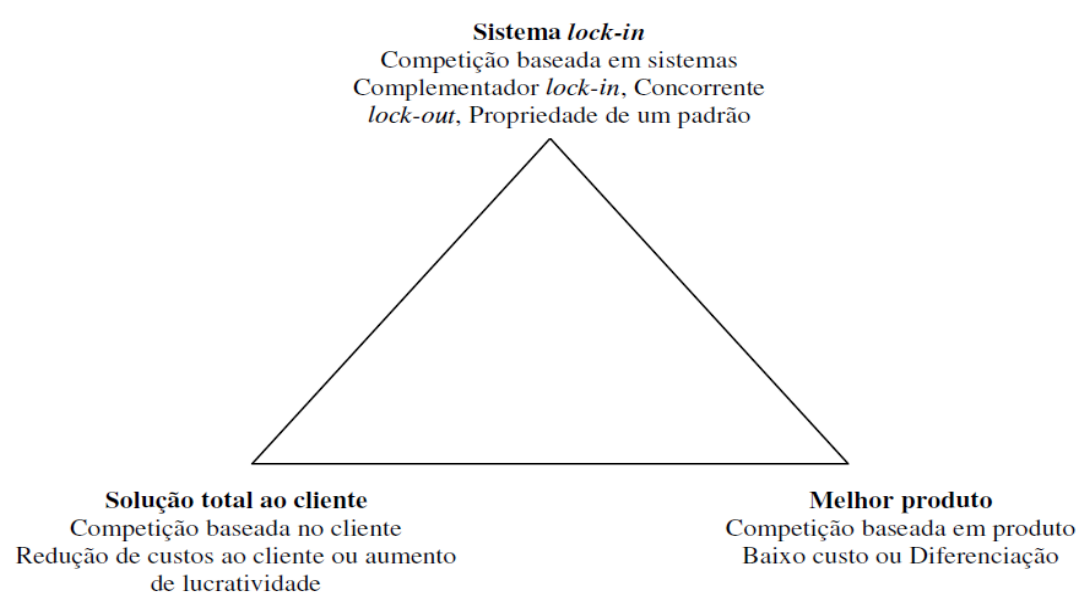

\section{Figura 1}

Modelo Delta: três distintas opções estratégicas.

Fonte: Hax, A. C., \& Wilde II, D. L. (2001). The delta projetct: discovering new sources of profitability in a networked economy. Great Britain: Palgrave.

Os modelos clássicos de estratégia enfatizam uma orientação mais forte para o produto, centrada na melhor oferta, seja via qualidade, custo, atributos ou a combinação dessas variáveis. O modelo delta de Hax e Wilde (2001) coloca o consumidor como o centro do desenvolvimento da estratégia competitiva, sendo o objetivo principal a capacidade da empresa em atrair, satisfazer e reter seus clientes. Essa capacidade é oriunda de melhor conhecimento do consumidor, com o intuito de criar uma relação mais próxima (Doligalski, Zaborek, \& Sysko-Romańczuk, 2015). De acordo com Hax e Wilde (2001), tal relação é extremamente importante e deve ser cultivada independentemente do produto que está sendo ofertado, uma vez que por meio dela pode-se criar uma posição competitiva superior para a empresa.

Esse relacionamento/vínculo com o cliente emerge como elemento decisivo para configurar a estratégia. Hax e Wilde denominam customer bonding o mecanismo de criação de vínculos quase indissociáveis com os clientes, o que é 
feito diretamente pelo cliente ou por meio de complementares com quem ele se relaciona (Ferreira, 2012).

Para os autores, os clientes e complementadores devem representar o centro da estratégia e o Modelo Delta, a essência de como a empresa deve competir e servir seus clientes no mercado. O Modelo Delta define três opções estratégicas representadas nos vértices do triângulo: a) melhor produto; b) soluções totais para o cliente; c) lock-in do sistema.

A melhor estratégia de produto baseia-se na forma clássica da concorrência, afirmando que só há duas maneiras de vencer: baixo custo ou diferenciação. $O$ problema é que a distinção raramente é uma fonte de vantagem competitiva sustentável, porque, uma vez que a estratégia é desenvolvida e se torna conhecida, a tecnologia frequentemente permite a imitação rápida que neutraliza a vantagem competitiva procurada (Hax \& Wilde, 2003; Doligalski, Zaborek, \& SyskoRomańczuk, 2015).

Os clientes de empresas que adotam esse posicionamento são atraídos por características intrínsecas do produto, sendo pela diferenciação que gera ao produto características únicas, geralmente elevando o preço final para clientes que estão dispostos a pagar por essa diferenciação, ou pelo baixo custo que gera ao produto diferenciais de competitividade em preço (Quadros Jr., 2005).

Contudo, Hax e Wilde (2003) chamam a atenção para o fato de que a posição no custo não deixa muito espaço para o sucesso, afinal de contas, segundo os autores, quantas são as empresas que podem simultaneamente desfrutar dos benefícios de um baixo custo?

$\mathrm{Na}$ opção do melhor produto, o foco das atenções da empresa é nos concorrentes, gerando pouca ou nenhuma ação junto ao cliente. Todos os esforços são destinados à competição de produtos (Ferreira, 2012).

Hax e Wilde (2003, p. 15) criticam a orientação exclusiva pelo melhor produto ao argumentarem que "dadas as características estruturais adversas da melhor posição de produto, em muitas situações, é preciso perguntar por que muitas empresas caem na armadilha de aceitar isso como a única opção disponível".

A opção estratégica de solução total para o cliente é oposta à abordagem de melhor produto (Hax \& Wilde, 2001). Entre os aspectos mais marcantes desse posicionamento estão o conhecimento profundo e o estreito relacionamento com o 
cliente. O objetivo é estar em linha com as expectativas e desejos do cliente, focando a economia do cliente, e não a economia do produto (Aghazadeh, 2015).

A proximidade do cliente permite que uma empresa antecipe suas necessidades e opere em conjunto para desenvolver produtos novos e diferenciados. Intensificar a aprendizagem do cliente para antecipar-se às suas necessidades produz efeito duplo: permite que o cliente aprenda a utilizar um produto ou serviço novo, acarretando redução de custo; e aprender a identificar as necessidades dos clientes aumenta a capacidade de as empresas satisfazê-las (Ferreira, 2012; Aghazadeh, 2015).

A posição estratégia de solução total para o cliente pode configurar-se de três maneiras, segundo Hax e Wilde (2001):

a) redefinição da experiência do cliente: consiste na mudança do relacionamento com o cliente, desde a compra do produto até o fim da sua vida útil;

b) escopo horizontal, ou seja, montar um pacote de produtos para satisfazer ampla gama de necessidades do cliente;

c) integração com o cliente, que pode significar terceirização ou a empresa realizar tarefas anteriormente relegadas ao cliente.

A opção estratégica de lock-in do sistema é também chamada de aprisionamento no sistema. Nessa posição a empresa enfoca não somente o produto ou o cliente, mas também os outros atores do sistema que contribuem para a criação do valor econômico. Portanto, a posição de lock-in do sistema representa a forma mais forte de amarração. Nessa posição, merece especial atenção o componente denominado por complementador. Segundo Nalebuff \& Brandenburger (1996, p. 18), "um participante é um complementador se os clientes valorizarem mais seu produto nas situações em que ele se apresentar acompanhado do produto de outro participante do que nas situações em que ele apresentar-se isoladamente".

Complementadores são provedores de produtos e serviços que elevam, direta ou indiretamente, a oferta da empresa e que a tornam mais atrativa para os compradores (Hax \& Wilde, 2001).

Para atrair e satisfazer os clientes, a empresa necessita também atrair, satisfazer e reter os complementadores, o que muda a preposição de valor para o sistema, em virtude da maior participação de componentes, criando uma cadeia de 
valor relevante em que todos ingressam em uma zona econômica de retornos e expansão crescentes (Hamza, 2009).

A ocorrência do lock-in depende do atendimento de duas condições: existência de retornos marginais crescentes e efeitos da rede externa de trabalho. Assim, retornos marginais crescentes demonstram a elevação de valor de um produto ou serviço em decorrência do aumento do número de usuários e da identidade de uso. A rede externa de trabalho reflete a atratividade do produto, uma vez que esta resulta não das características do produto, mas dos investimentos realizados, especialmente por clientes e complementadores. Portanto, a ocorrência dessas condições gera um ciclo virtuoso que beneficia todos os envolvidos (Hax \& Wilde, 2001; Doligalski, Zaborek, \& Sysko-Romańczuk, 2015).

O Modelo Delta foi utilizado para estudar o posicionamento estratégico da empresa pesquisada, antes e depois da desregulamentação estatal no setor de energia elétrica, adotando, para isto, a metodologia a seguir apresentada.

\section{Metodologia}

Para atingir o objetivo da pesquisa, foi realizado um estudo de caso descritivo de natureza qualitativa.

O principal método utilizado para a coleta de dados foi a entrevista semiestruturada que, no entendimento de Gil (1999) e Collis e Hussey (2006), deve ser desenvolvida a partir de uma relação organizada de perguntas, possibilitando ao investigador melhor coordenação na obtenção das informações. O roteiro de entrevista utilizado é constituído por 12 questões elaboradas para responder aos objetivos específicos desta pesquisa.

Malhotra (2006) define a unidade de observação como sendo os elementos amostrais por meio dos quais o pesquisador terá acesso às informações necessárias para a realização da pesquisa. Para a presente investigação, a unidade de observação foi constituída pelo corpo de coordenadores, gerentes e diretores da SAE Towers, composto por 16 colaboradores.

A Tabela 1 apresenta as áreas e os níveis hierárquicos de cada respondente, identificados pela letra $R$, seguida de um número para posterior identificação. 


\section{Tabela 1}

Caracterização dos respondentes

\begin{tabular}{lll}
\hline Respondente & Nível Hierárquico & Área \\
\hline R1 & Superintendente & Comercial e Marketing \\
R2 & Diretor & Comercial e Marketing \\
R3 & Diretor & Operações \\
R4 & Diretor & Financeiro \\
R5 & Gerente & Gerenciamento de Contratos \\
R6 & Coordenador & Produção \\
R7 & Coordenador & Comercial e Marketing \\
R8 & Coordenador & Comercial e Marketing \\
R9 & Coordenador & TI \\
R10 & Coordenador & Financeiro \\
R11 & Gerente & Engenharia \\
R12 & Gerente & Engenharia \\
R13 & Gerente & Suprimentos \\
R14 & Coordenador & Produção \\
R15 & Gerente & Construção \\
R16 & Coordenador & Qualidade \\
\hline
\end{tabular}

Fonte: dados da pesquisa, 2016.

Para examinar os resultados obtidos na pesquisa, foi utilizado o método denominado análise de conteúdo. Bardin (2006, p. 38) refere que a análise de conteúdo consiste em "um conjunto de técnicas de análise das comunicações, que utiliza procedimentos sistemáticos e objectivos de descrição do conteúdo das mensagens". A abordagem pela análise de conteúdo presta-se aos fins descritivos e explicativos e aos de verificação formulados no problema proposto. Segundo Vergara (2005, p. 15), "a análise de conteúdo é considerada uma técnica para o tratamento de dados que visa identificar o que está sendo dito a respeito de um determinado tema".

Os gestores foram entrevistados conforme roteiro de entrevistas elaborado com as seguintes dimensões: a) mudança de ambiente; b) estratégia corporativa; c) melhor produto; d) solução total para o cliente; e) lock-in do sistema. Teve-se o cuidado de registrar a correta percepção do entrevistado em cada dimensão pesquisada. Desta forma, o método de análise de conteúdo, permitiu analisar as entrevistas realizadas, com objetivo de identificar a adaptação e o posicionamento estratégico da empresa pesquisada, à luz do Modelo Delta, e cujos resultados são a seguir apresentados. 


\section{Apresentação e análise dos resultados}

A apresentação e análise dos resultados da pesquisa exploram inicialmente as transformações no ambiente de negócios e as estratégias adotadas pela SAE Towers frente às mudanças de mercado.

Entre as mudanças no setor elétrico, é possível criar um marco e separar a análise em duas fases, antes e depois da criação da ANEEL. A agência foi instituída a partir de um decreto em 1996; entretanto, foi fisicamente estabelecida em 1998 e somente no final do ano de 1999, com a regulamentação do mercado e o primeiro leilão de energia, a ANEEL iniciou sua atuação.

No período que antecedeu a criação da ANEEL, as expansões do setor de transmissão eram planejadas e executadas pelas empresas estatais. A Eletrobrás planejava a expansão em conjunto com as concessionárias estaduais, que eram responsáveis pela realização do projeto de desenvolvimento. Nessa primeira fase o domínio do mercado foi quase em sua totalidade estatal e as negociações de vendas de energia ocorriam diretamente com as concessionárias de cada estado, como: CEMIG, CHESF, ELETROPAULO, FURNAS, entre outras.

Nessa fase, as concessionárias estaduais negociavam seus projetos diretamente com os fornecedores e optavam pela compra do serviço de engenharia de linha de transmissão, detalhamento de torres (ou estruturas), fabricação e montagem em campo, pois não possuíam engenharia disponível para essa atividade. A SAE Towers fornecia soluções completas, conhecidas como projetos turn key, em que o cliente definia o ponto de saída e chegada da linha de transmissão e todo o processo de execução era realizado pelo fornecedor.

Nesse ambiente, as relações comerciais eram focadas na confiança da empresa, na qualidade dos produtos e no prazo de entrega. R2 é claro ao afirmar: "as negociações antes da criação da ANEEL sempre foram baseadas na parceria, confiança e velocidade de entrega, o preço não era fator decisivo". R1 relata que "por diversas vezes iniciavam a fabricação de um projeto antes do término das condições financeiras e assinatura do contrato".

A fase pós-criação da ANEEL foi caracterizada pela abertura de mercado à participação de empresas privadas e pela mudança na forma de remuneração e disputa pelas concessões, dando-se início à era dos leilões. 
Nesse novo modelo, várias empresas privadas nacionais e internacionais obtiveram vantagem financeira ao adquirir projetos (lotes de energia elétrica) em leilões da ANEEL, o que as permitiam se tornar empresas transmissoras. Com isso, os lotes dos leilões de energia começaram a ser disputados.

O leilão é realizado tendo como valor de referência a maior RAP - Receita Anual Permitida, e a diferença entre o valor de referência e a oferta à menor do lance é conhecida como deságio. A disputa nos leilões promoveu deságios em função da concorrência existente entre as empresas participantes. O vencedor constituía o proponente que oferecesse como lance o menor valor de RAP. Nessa nova fase, os clientes da SAE Towers foram os vencedores dos leilões, em sua maioria empresas privadas ou consórcios entre as empresas privadas ou públicoprivadas.

R1 relata que a principal mudança de cenário no setor foi a criação da ANEEL, por dois motivos: a) primeiro, houve uma demanda muito maior por linhas de transmissão, já que, logo após a ANEEL iniciar as suas atividades, o Brasil passou pelo racionamento de energia em 2001, obrigando o governo a retomar os investimentos no setor; b) devido às relações comerciais, no início as empresas públicas ou seus consórcios dominaram os leilões, mas logo depois as empresas privadas brasileiras e internacionais se tornaram mais proeminentes.

R2 também cita a mudança de regulação como principal mudança no setor e observa que "antes conhecíamos todos os nossos clientes, após a regulação, apareceram muitos outros". Na Figura 2 pode-se verificar a natureza das empresas vencedoras de lotes de energia nos leilões no período de 2000 a 2015.

\section{Figura 2}

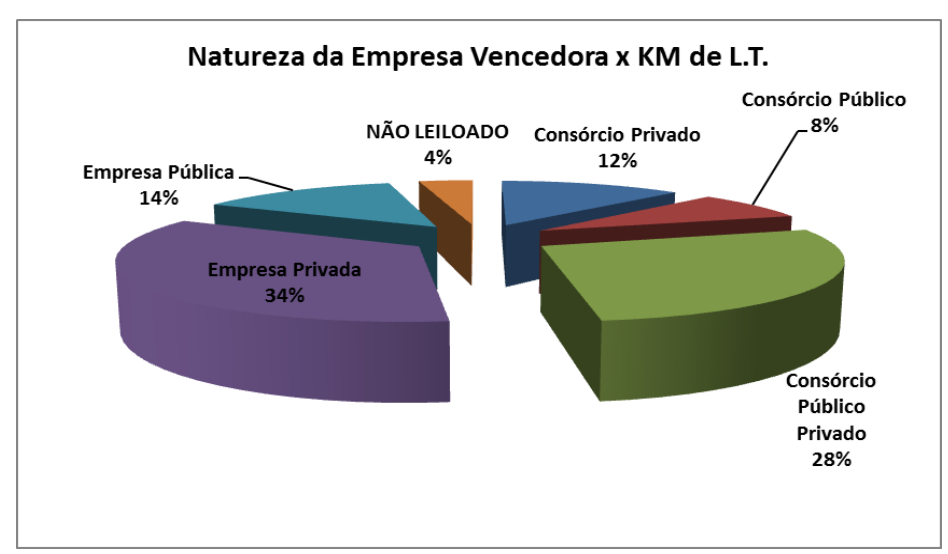

Natureza das empresas vencedoras de lotes nos leilões de 2000 a 2015 por km de linha de transmissão.

Fonte: dados da pesquisa, 2016. 
Com novos clientes e um mercado com foco principal em ganhos financeiros, ocorreu uma mudança na relação cliente-fornecedor. Antes, a relação era baseada em confiança, credibilidade e qualidade. No novo cenário, os clientes preocupavamse fortemente com o preço, devido aos deságios promovidos para obtenção de projetos e por terem o perfil de empresa privada.

R1, R2, R3, R4 e R5 referem-se em suas falas à queda no preço de venda de estruturas de transmissão de energia elétrica após o ano de 2003, devido aos deságios nos leilões e à nova forma de negociação, com principal ênfase no preço.

Observa-se na Figura 3 a significativa participação de empresas estrangeiras no mercado brasileiro de linhas de transmissão de energia elétrica.

\section{Figura 3}

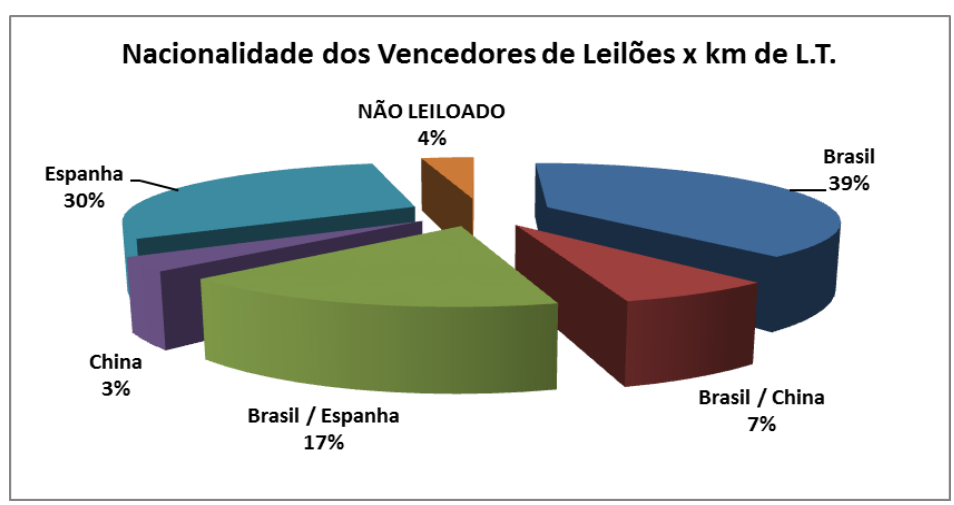

Nacionalidade dos vencedores de lotes nos leilões de 2000 a 2015 por km de linha de transmissão.

Fonte: dados da pesquisa, 2016.

Para garantir sua sobrevivência, a empresa investigada precisou desenvolver novas estratégias, buscando manter o seu posicionamento de líder no mercado. Conforme R1, a empresa precisava de três estratégias iniciais: a) olhar para o novo mercado e verificar suas necessidades; b) apresentar a SAE Towers para os novos clientes; c) aproximar-se dos clientes, principalmente dos que possuíam menor conhecimento do produto, e oferecer soluções completas.

Segundo R1, o novo mercado, apesar do foco do cliente no preço, também exigia um fornecedor com capacidade de produção, qualidade e entregas no prazo. Estes fatores constituíam diferenciais para projetos grandes, pois o sequenciamento de obra dependia do recebimento de torres completas. De acordo com o entrevistado, era necessário 
trazer os novos clientes à SAE Towers, apresentar a empresa, seus colaboradores, sua estrutura e o seu histórico. Mostrar o diferencial de uma fábrica moderna com mais de 50 anos de existência. Oferecer soluções completas, engenharia, testes, proximidade com a engenharia do cliente, fornecimento orientado à obra.

Para R1, tornava-se também fundamental não perder nenhuma concorrência, oferecendo preços competitivos.

O entrevistado R2 reconheceu que a empresa precisou apresentar-se para os novos clientes e também enfatizou que o histórico da empresa constituiu um fator importante, pois "nos consórcios público-privados, estavam presentes as empresas públicas, clientes SAE Towers há décadas".

Adaptando-se ao ambiente de mercado, a SAE Towers estreitou 0 relacionamento com os seus clientes, o que permitiu identificar, no novo perfil de consumidores, uma grande carência de engenharia do produto. Dessa forma, complementando a utilização de sua capacidade de produção, a empresa desenvolveu uma nova unidade de negócio voltada para o gerenciamento de projetos executados por terceiros, aumentando, assim, sua abrangência e proximidade com o cliente. Os pesquisados R11 e R12 mencionaram que a estratégia de gerenciar a execução de projetos terceirizados, agregou valor ao cliente, proporcionando-lhe uma tarefa que exige elevado nível de conhecimento e permitir a adequação do projeto ao know-how da SAE Towers.

Utilizando-se do know-how desenvolvido, a SAE Towers passou a oferecer uma solução por componente, conhecida como piquete, que agregava valor à embalagem do produto. Nesse modelo a empresa fornece a torre embalada por componentes, absorvendo parte do trabalho executado em campo pelo cliente. Todos os entrevistados aludiram ao fornecimento por piquete como um diferencial da empresa sobre os concorrentes.

Nesse formato, a SAE Towers produz as posições da torre e na etapa de embalagem realiza toda a logística interna de montagem e identificação dos amarrados por componentes. Dessa forma, a empresa retirou parte do custo que o cliente tinha em campo, agilizando o processo de montagem em campo e reduziu o espaço necessário para estoque no pátio.

O entrevistado R1 salienta que o sucesso dessa solução foi rapidamente incorporado pelo mercado e concorrentes. Em todos os novos empreendimentos os 
clientes passaram a solicitar a entrega do produto embalado por piquete, procedimento adotado em todos os grandes projetos após 2010, incluindo as duas linhas da usina de Belo Monte.

Em relação ao posicionamento estratégico da SAE Towers, foi possível observar uma forte consistência entre os 16 colaboradores entrevistados, afirmando que a excelência na qualidade dos produtos e a velocidade na entrega mantêm a SAE Towers como empresa líder no setor.

A equipe de comercial e marketing ( $R 1, R 2, R 7$ e $R 8$ ) comenta que, em relação ao posicionamento competitivo, a empresa atualmente busca oferecer diferenciação em seu produto. Dos 16 respondentes, 10 afirmaram que a proximidade com o cliente e a inovação tornam a SAE Towers a empresa com os melhores produtos do mercado. Outros três respondentes, de níveis hierárquicos mais altos, entendem que o conjunto de produtos e serviços oferecidos já compreende uma oferta de solução total ao cliente, como proposto por Hax e Wilde (2001).

Conforme relatado pelos diretores ( $R 1, R 2, R 3$ e $R 4)$, com o surgimento de novos clientes, após a regulação do mercado pela ANEEL, a SAE Towers adotou as estratégias apresentadas, para manter o seu posicionamento competitivo em um mercado focado no menor preço. As estratégias adotadas estão contempladas no processo adaptativo do modelo Delta de Hax e Wilde (2001):

a) efetividade operacional: produção e entrega de produtos e serviços;

b) foco no cliente: gestão da interface com o cliente;

c) inovação: processo de desenvolvimento de novos produtos.

É claro para todos os entrevistados que o novo posicionamento está fortemente associado a outros três pontos fortes reconhecidos pelo mercado: capacidade de fabricação, qualidade e inovação de processo e parceria com os clientes. O mercado reconhece que as principais novidades estão sendo trazidas ao mercado pela SAE Towers, com ênfase maior na solução total para o cliente. A parceria com os consumidores, durante o processo de engenharia, prevê a elaboração de soluções que aperfeiçoem a construção do projeto e reduzam custos.

A SAE Towers tem como estratégia fornecer o melhor produto, com a melhor solução e a maior velocidade de entrega do mercado. Esse posicionamento no triângulo do modelo Delta de Hax e Wilde se opõe ao posicionamento de menor preço. Para tanto, é necessário apresentar ao cliente o diferencial na oferta dos @ $\Theta \Theta$ Revista Gestão \& Tecnologia, Pedro Leopoldo, v. 17, n. 1, p. 181-206, jan./abr. 2017200 
produtos e serviços oferecidos pela empresa. Foram oito os colaboradores que ponderaram que o diferencial na oferta de produtos e serviços da SAE Towers é fundamentado em soluções que geram um diferencial para o cliente.

A identificação do valor para o cliente nasce com a proximidade com o mesmo, desde a correta elaboração do orçamento até a definição da melhor alternativa técnica para o projeto. Ferreira (2012) afirma que aprender a identificar as necessidades dos clientes aumenta a capacidade de as empresas em satisfazê-las.

$\mathrm{Na}$ etapa de identificar e explorar inovações valorizadas pelo cliente, como oferta de produtos e serviços de valor superior, diversas ações foram aludidas pelos respondentes. Primeiramente, quatro respondentes afirmaram que essas inovações são difundidas entre todos os setores, em reuniões realizadas semanalmente. Quando as inovações são consideradas pertinentes, passam a ser incorporadas ao processo, com objetivo de criar um diferencial para o produto, possibilitando, assim, vantagens nas negociações.

Os diferenciais proporcionados pelas inovações foram apontados, pelos diretores, como argumentos exclusivos em negociações, durante a abordagem de pré-venda e de pós-venda, e comunicados desde o delineamento da proposta até a entrega do produto.

O know-how desenvolvido pela empresa possibilita que diferentes departamentos trabalhem em conjunto, de forma a oferecer soluções customizadas, em especial para os clientes-chave da empresa, além do desenvolvimento de novos produtos e soluções.

Outros sete respondentes citaram a capacidade industrial da SAE Towers como fator-chave de sucesso, visto que é de fundamental importância para o cliente poder contar com a agilidade do processo produtivo para o sucesso de seus empreendimentos.

Foi destacado, por entrevistados de todas as áreas da empresa, que a prestação de serviços, associada aos produtos da SAE Towers proporciona alto valor agregado ao cliente. Para os setores de produção e engenharia, o valor que é agregado ao negócio do cliente por meio dos serviços proporcionados pela empresa deve ser destacado durante a negociação comercial. É de fundamental importância que a empresa comunique o valor superior proporcionado ao consumidor, de forma 
eficaz, como sustentação da estratégia de fidelização do cliente e de obtenção de preço superior pela oferta diferenciada (Hamza, 2009).

A Tabela 2 apresenta as estratégias adotadas pela SAE Towers à luz do Modelo Delta, destacando as três posições estratégicas: melhor produto; solução total para o cliente; e lock-in do sistema.

\section{Tabela 2}

Resumo das estratégias identificadas

\begin{tabular}{|c|c|c|c|}
\hline & Melhor Produto & Solução total ao cliente & Sistema Lock-in \\
\hline \multirow{3}{*}{ 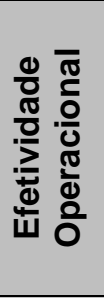 } & Custo do melhor produto & $\begin{array}{l}\text { Benefício do melhor } \\
\text { cliente }\end{array}$ & $\begin{array}{l}\text { Performance do melhor } \\
\text { sistema }\end{array}$ \\
\hline & Melhor produto & $\begin{array}{l}\text { Entrega por componente / } \\
\text { Piquete }\end{array}$ & $\begin{array}{l}\text { Maior capacidade do } \\
\text { mercado }\end{array}$ \\
\hline & Melhor qualidade & $\begin{array}{l}\text { EPC Construção de L.Ts / } \\
\text { Solução Total }\end{array}$ & Entrega mais rápida \\
\hline \multirow{6}{*}{ 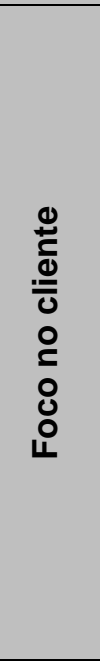 } & $\begin{array}{l}\text { Foco nos canais de } \\
\text { distribuição }\end{array}$ & Foco no cliente & $\begin{array}{l}\text { Foco na arquitetura do } \\
\text { sistema }\end{array}$ \\
\hline & $\begin{array}{l}\text { Proximidade com } \\
\text { engenharia do cliente }\end{array}$ & $\begin{array}{l}\text { Ofertar entregas / soluções } \\
\text { customizadas }\end{array}$ & $\begin{array}{c}\text { Engenharia com foco na } \\
\text { solução }\end{array}$ \\
\hline & $\begin{array}{c}\text { Identificar reduções de } \\
\text { custo para o cliente em } \\
\text { nossa solução }\end{array}$ & $\begin{array}{l}\text { Maximizar participação no } \\
\text { cliente }\end{array}$ & $\begin{array}{c}\text { Antever problemas para o } \\
\text { cliente }\end{array}$ \\
\hline & & $\begin{array}{l}\text { Engenharia em contato } \\
\text { contínuo com o cliente }\end{array}$ & \\
\hline & & $\begin{array}{c}\text { Antecipar a solução para o } \\
\text { cliente }\end{array}$ & \\
\hline & & $\begin{array}{c}\text { Apresentar ao cliente as } \\
\text { vantagens do produto SAE } \\
\text { Towers }\end{array}$ & \\
\hline \multirow{5}{*}{ 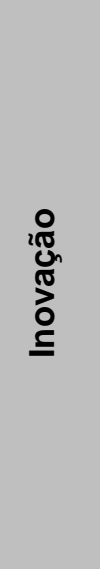 } & Inovação do produto & $\begin{array}{l}\text { Inovação no serviço ao } \\
\text { consumidor }\end{array}$ & Inovação do sistema \\
\hline & $\begin{array}{l}\text { Entrega por componente / } \\
\text { Piquete }\end{array}$ & $\begin{array}{l}\text { Solução completa: } \\
\text { Engenharia, Fornecimento } \\
\text { e Construção }\end{array}$ & Criar lock-in do cliente \\
\hline & & $\begin{array}{l}\text { Customizar solução para o } \\
\text { cliente }\end{array}$ & $\begin{array}{l}\text { Engenharia com foco no } \\
\text { cliente }\end{array}$ \\
\hline & & & $\begin{array}{l}\text { Participar da solução do } \\
\text { cliente }\end{array}$ \\
\hline & & & $\begin{array}{c}\text { Apresentar ao cliente as } \\
\text { vantagens do produto SAE } \\
\text { Towers }\end{array}$ \\
\hline
\end{tabular}

Fonte: dados da pesquisa, 2016.

A Tabela 2 mostra que as estratégias de negócios da empresa demonstram fortes evidências para o posicionamento de "solução total para o cliente". Esse 
posicionamento estratégico requer que a empresa ofereça também o melhor produto e a melhor qualidade em produtos e serviços. Entretanto, a empresa tem envidado os melhores esforços para oferecer uma solução completa e customizada para as necessidades dos clientes, integrando engenharia, fornecimento e construção. $O$ esmero nessa posição estratégica tem garantido à empresa a manutenção da sua liderança de mercado.

\section{Considerações Finais}

Nas últimas décadas, o Setor Elétrico Brasileiro - SEB foi submetido a intensas transformações. A criação da Agência Nacional de Energia Elétrica (ANEEL), em dezembro de 1996, com efetiva operação a partir de 1998, inaugurou uma nova era da regulação e da fiscalização do segmento de energia elétrica no país. A transferência do modelo estatal para o privado possibilitou a expansão do SEB por empresas privadas e pela realização de concorrências públicas, cabendo à ANEEL o papel de agente regulador do setor.

A presente investigação teve como objetivo descrever as transformações no ambiente empresarial do setor de energia elétrica e analisar as decorrentes adaptações estratégicas de uma empresa que atua no segmento de linhas de transmissão. Para isso, foi realizada uma pesquisa de natureza qualitativa com o corpo de coordenadores, gerentes e diretores da organização, totalizando 16 colaboradores.

Para interpretar o processo estratégico da organização, no contexto do ambiente competitivo e globalizado contemporâneo, o Modelo Delta, de Hax e Wilde, foi selecionado por oferecer um arcabouço diferenciado. As estratégias adotadas pela empresa foram analisadas à luz Modelo Delta, destacando as três posições estratégicas: melhor produto; solução total para o cliente e lock-in do sistema.

Com a abertura de mercado e desestatização do setor, a empresa pesquisada, líder no setor, passou a atuar em um novo mercado com novos players e novas regras de competição. O aumento de concorrência com foco no preço obrigou a organização a rever o seu posicionamento competitivo e de mercado. Foi nesse processo que se inseriu a gestão do valor para o cliente, que é um processo de marketing fundamental para que a empresa obtenha vantagem competitiva e ofereça 
valor superior ao cliente, contribuindo, consequentemente, para o alcance de seus objetivos de crescimento de forma sustentável.

A análise das estratégias adotadas pela SAE Towers indicaram forte orientação para mercado, identificada em empresas submetidas a ambientes altamente competitivos e que visam o desempenho superior. A orientação para mercado sugere foco no cliente, no concorrente e nas transformações do ambiente de negócios, além de boa integração funcional, o que pressupõe a necessidade de integrar e direcionar a cultura empresarial para o contínuo monitoramento do ambiente externo.

Em um ambiente de mercado competitivo, a empresa precisou intensificar o relacionamento com os seus clientes, e com isso pôde observar grande carência de engenharia do produto. Criando uma nova unidade de negócio voltada para o gerenciamento de projetos executados por terceiros, desenvolveu, dessa forma, maior abrangência e proximidade com o cliente. A identificação do valor para o cliente foi possível devido à maior proximidade com o mesmo, proporcionando à empresa a competência em satisfazê-lo.

O posicionamento da organização está fundamentado em soluções que geram um diferencial para o cliente. A empresa tem como estratégia fornecer 0 melhor produto, com a melhor solução e a maior velocidade de entrega do mercado. Esse posicionamento no triângulo do modelo Delta de Hax e Wilde é contrário ao posicionamento de menor preço. Para manter-se líder de mercado assumindo o posicionamento estratégico identificado na presente investigação, a empresa necessita continuar inovando e oferecendo novas soluções que proporcionem valor superior ao cliente.

\section{Referências}

Agência Nacional de Energia Elétrica - ANEEL. (2013). Editais de leilão ANEEL n 01/2013 11/2013. Recuperado de: http://www.aneel.gov.br/ aplicacoes/editais _transmissao/edital_transmissao.cfm.

Agência Nacional de Energia Elétrica - ANEEL. (2008). Relatório ANEEL 10 Anos. Brasilia: ANEEL.

Agência Nacional de Energia Elétrica - ANEEL. (2016). Resultados dos Leilões 2000 a 2015.x/s Recuperado de: http://www.aneel.gov.br/documents/654791/ 0/SCT_RESULTADO_LEIL\%C3\%830_INTERNET_19nov2015.xlsx. 
Aghazadeh, H. (2015). Strategic Marketing Management: Achieving Superior Business Performance through Intelligent Marketing Strategy. Procedia-Social and Behavioral Sciences, 207, 125-134.

Bardin, L. (2006). Análise de conteúdo (L. de A. Rego \& A. Pinheiro, Trads.). Lisboa: Edições 70 .

Bhawsar, P., \& Chattopadhyay, U. (2015). Competitiveness: review, reflections and directions. Global Business Review, 16(4), 665-679.

Carvalho, R. G. (2011). Análise dos resultados dos leilões de transmissão de energia elétrica no Brasil. (Dissertação de Mestrado em Regulação e Gestão de Negócios. Universidade de Brasília, UnB, Brasília, DF, Brasil).

Collis, J., \& Hussey, R. (2005). Pesquisa em Administração: um guia prático para alunos de graduação e pós-graduação (2a ed.), Porto Alegre: Bookman.

Companhia Energética de Minas Gerais - CEMIG (2016). A história da eletricidade. Recuperado de http://www.cemig.com.br/pt-br/a_cemig/Nossa_ Historia/Paginas/historia_da_eletricidade_no_brasil.aspx.

Doligalski, T., Zaborek, P., \& Sysko-Romańczuk, S. (2015). Value proposition and firm performance: segmentation of Polish online companies. International Journal of Business Performance Management, 16(2-3), 133-148.

Ferreira, T. F. (2012). Posicionamento competitivo em economias de redes: uma aplicação do modelo delta em mercados de baixa diferenciação. (Tese de Doutorado em Administração. Universidade de São Paulo, USP, São Paulo, SP, Brasil).

FUSP. (2015). A história da eletricidade no brasil. Recuperado de http://sel.eesc.sc.usp.br/protecao/conteudohistoricobrasil.htm

Gil, A. C. (1999). Métodos e técnicas de pesquisa social (5a ed.). São Paulo: Atlas S.A.

Gomes, A. C. S., Abarca, C. D. G., Faria, E. A. S. T., \& Fernandes, H. H.O. (2006). O setor elétrico. Recuperado de <http://www.bndes.gov.br/ conhecimento/livrosetorial/setorial14.pdf>.

Hamza, K. M. (2009). Gestão do valor para o cliente e posicionamento estratégico: um estudo de caso no mercado empresarial. (Tese de Doutorado em Administração Universidade de São Paulo, USP, São Paulo, SP, Brasil).

Hamel, G., \& Prahalad, C. K. (1994). Competing for the future. Boston: Harvard Business School Press.

Hax, A. C., \& Wilde II, D. L. (2001). The delta projetct: discovering new sources of profitability in a networked economy. Great Britain: Palgrave. 
Hax, A.C., \& Wilde, D.L. (2003). The delta Model: a new framework of strategy. Journal of strategic management education. Dublin: Senate Hall Academic, 1-21.

Harrison, J. (2005). Administração estratégica de recursos e relacionamentos. Porto Alegre: Bookman.

Januzzi, A. C. (2007). Qualidade de energia elétrica sob o foco do consumidor. (Dissertação de Mestrado em Regulação e Gestão de Negócios Universidade de Brasília, UnB, Brasília, DF, Brasil).

Malhotra, N. (2006). Pesquisa de marketing: uma orientação aplicada (4a ed.). Porto Alegre: Bookman.

Nason, R. S., \& Wiklund, J. (2015). An Assessment of Resource-Based Theorizing on Firm Growth and Suggestions for the Future. Journal of Management, $X X(\mathrm{X}), 1$ 29.

Nalebuff, B. J., \& Brandenbuger, A. M. (1996). Co-opetição. Um conceito revolucionário que combina competição e cooperação. Rio de Janeiro: Rocco.

Ponchirolli, O., \& Fialho, F. A. P. (2016). Gestão estratégica do conhecimento como parte da estratégia empresarial. Revista da FAE, 8(1).

Porter, M. E., \& Fuller, M. (1986) Coalitions and global strategy. In Competition global industries. Boston: Harvard Business School Press.

Porter, M. E. (1991). How competitive forces shape strategy. 1979. In M. E. Porter. Strategy: seeking and securing competitive advantage. Boston: Harvard Business School Publishing Division.

Quadros Jr., A. (2005). Orientação para o mercado e o modelo Delta de estratégia. (Dissertação de Mestrado em Administração. Faculdade de Economia e Administração da Universidade de São Paulo, USP, São Paulo, SP, Brasil).

Salavou, H. E. (2015). Competitive strategies and their shift to the future. European Business Review, 27(1), 80-99.

Toledo, G. L., \& Rubal, J. M. (2003). Estratégia de crescimento e estratégia competitiva em marketing: um estudo de caso de lançamento de produto em uma organização prestadora de serviço. Anais do VIo SEMEAD, São Paulo, SP, Brasil.

Valdés, J. A. (2003) Marketing estratégico e estratégia competitiva de empresas turísticas: um estudo de caso da cadeia hoteleira Sol Meliá. São Paulo: FEAUSP.

Vergara, S. C. (2005). Projetos e relatórios de pesquisa em Administração (6a ed.). São Paulo: Atlas. 